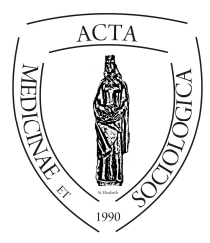

Acta Medicinae et

Sociologica (2020)

UNIVERSITY OF

DEBRECEN

Vol. 11. No. 30. (32-42)

FACULTY OF

HEALTH

doi:

NYÍREGYHÁZA

\title{
Quality of Life of Patients with Arrhythmia
}

\author{
Chloubová Ivana ${ }^{1}$, Bulava Alan ${ }^{2}$ \\ ${ }^{1}$ University of South Bohemia in České Budějovice, Faculty of Health and Social Sciences, Institute of Nursing, \\ Midwifery and Urgent Care \\ ${ }^{2}$ University of South Bohemia in České Budějovice, Faculty of Health and Social Sciences, Institute of Nursing, \\ Midwifery and Urgent Care
}

\section{INFO ABSTRACT}

Chloubová Ivana

chloubo@zsf.jcu.cz

\section{Keywords: \\ Quality of life, arrhythmia, health, restlessness}

\begin{abstract}
.
Introduction: Quality of life must be perceived in two levels objective and subjective. Heart arrhythmia is a disease of the cardiovascular system that, by its subjective and objective symptoms, can affect the individual's life physically, mentally, and also socially. It can limit a person in his or her everyday activities or in activities that make them happy or satisfied.

Objectives: The aim of the research was to map the quality of life of patients with arrhythmia and to verify whether the duration of arrhythmia has an effect on the quality of life of patients with arrhythmia.

Methods: A standardized ASTA (Arrhythmia - Specific Questionnaire in Tachycardia and Arrhythmias) questionnaire was used to collect quantitative data. The research group consisted of adult patients diagnosed with hearth arrhythmia, hospitalized at the Department of Cardiology of the Ceske Budejovice Hospital (Nemocnice České Budějovice a.s.). A total of 127 valid questionnaires were used for data processing.

Results: The research revealed that the most common symptom of arrhythmia in 58\% cases was rapid heartbeat, irregular heartbeat, and a sense of heart failure. Most respondents agreed with the claim that heart rhythm disorder makes it impossible for them to perform work, study, and perform daily life activities. No statistically significant differences were found in the evaluation of the influence of the arrhythmia duration on the patients' quality of life.

Conclusions: Arrhythmia duration in the selected sample does not affect the overall health status and quality of life measured by the ASTA series questionnaires. Arrhythmia restricts the patient to perform work tasks, study, and perform daily life activities.
\end{abstract}




\section{Introduction}

The quality of life must be perceived in two levels - objective and subjective. The subjective quality of life is about human emotionality and general satisfaction with life, while the objective one considers fulfilment of the requirements regarding material and social conditions of life, social status, and physical health (Payne, 2005). For medicine and health care, the definitions that correspond to the World Health Organization (WHO) understanding of health are relevant, with health not defined only as an absence of illness, but as a state of complete physical, psychological, and social well-being (Health 2020). The quality of life is the state the individual perceives with respect to the value systems and cultural habits and traditions in which he or she lives, in relation to his or her personal goals, expectations, interests, and lifestyle (Ustun, 1994). The concept of the quality of life has been used in medicine since the $1970 \mathrm{~s}$, specifically in relation to the medical and health care interventions provided. Doctors are interested in the quality of life of people with various illnesses or the impact of their therapy on the quality of life of the treated persons.

Heart arrhythmia is a disease of the cardiovascular system that, by its subjective and objective symptoms, can affect the individual's life physically, mentally, and also socially. It can limit a person in their everyday activities or in activities that make them happy or satisfied. Arrhythmias mean disturbances of heart rhythm that can be divided according to various criteria (Sovová et al., 2004). The simplest division is based on the frequency of heart rhythm, with a heart rate lower than 50 / min. being called bradyarrhythmia; on the contrary, tachyarrhythmia is characterized by a frequency greater than $100 / \mathrm{min}$. Arrhythmias occur as either paroxysmal, non-permanent (ventricular tachycardia up to $30 \mathrm{~s}$ ), incessant (continuous, usually longer than 12 hours), or permanent (usually with ventricular tachycardia over 30 s) (Bulava, 2017).

Chrobák et al. (2007) describes clinical manifestations of tachyarrhythmia as unpleasant subjective feelings of the patient - the patient usually complains about palpitations that may or may not be accompanied by chest pain and shortness of breath. Patients usually report increased fatigue, reduced load tolerance, sometimes presyncope or even syncope (sudden transient loss of consciousness). Bradyarrhythmias are manifested by a slow pulse; they may cause weakness, nausea, fainting, unpleasant eye sensations (seeing stars), vertigo, or a complete syncope. Patients often describe the subjective feeling of fatigue, faintness, lack of performance, or dyspnoea.

The tools that can measure the quality of life are different. A questionnaire survey seems to be the most suitable. Currently, the most widely used questionnaire is SF 36, which is a widely used tool for determining health-related quality of life. In addition, specific questionnaires are used for a particular type of illness; e.g. to measure the quality of life of patients with arrhythmia (AST) (Arrhythmia - Specific Questionnaire in Tachycardia and Arrhythmias) is used. This questionnaire focuses on problems with heart rhythm disorders, monitoring the symptoms specific to arrhythmia and the quality of life related to health in patients with heart rhythm disorders. The questionnaire was designed by Ulla Walfridsson (Linköping, Sweden) and it is divided into three parts. 
The research maps the quality of life of patients with cardiac arrhythmia and the possibilities of nursing interventions in the provision of nursing care. The thesis brings a complex view of the problematics of the life quality of patients suffering from arrhythmia when this is not only a medical problem but it also influences patient's mental and social well-being.

\section{Methods}

"Questionnaire". The standardized ASTA (Arrhythmia - Specific Questionnaire in Tachycardia and Arrhythmias) was used to collect quantitative data, focusing on heart rhythm disorders, monitoring the symptoms specific to arrhythmia and the quality of life related to health in patients with heart rhythm disorders. The questionnaire was designed by Ulla Walfridsson (Linköping, Sweden) and it is divided into three parts (an original version in Czech was also delivered). The questionnaire consists of 23 questions, with the question identifying the symptoms of the disease having 9 sub-questions. The structure of the questions is similar; the respondent is asked to mark one variation of the answer; one question allows the respondent to mark more answers. Two questions are constructed as filtering - if a positive answer to the question asked is chosen, the respondent is provided with extra space to fill additional statement in. The questionnaire is divided into three parts; the first one identifies the duration of the heart rhythm disorders and possible medication, the second part follows the specific symptoms of arrhythmia (typical and maximum duration of arrhythmia, dyspnoea, fatigue, chest pressure, restlessness, anxiety, weakness, faintness, consciousness disorder, etc.), and the third part of the questionnaire focuses on problems with heart arrhythmias in the context of coping with everyday activities. The questions asked are comprehensible and the questionnaire completion takes approximately 20 minutes. The research was carried out during the years 2016-2017.

\section{Characteristics of the Research Group}

The research group consisted of adult patients diagnosed with hearth arrhythmia, hospitalized at the Department of Cardiology of the Ceske Budejovice Hospital (Nemocnice České Budějovice a.s). There were 160 respondents addressed; 148 respondents were willing to fill in the questionnaire. Of the 148 submitted questionnaires, 21 questionnaires were filled in incompletely, 127 valid questionnaires were used to process the data. The age structure of the patients was in the range of their years of birth between 1939 - 1985; 29 respondents did not state their age (the age was not a direct part of the standardized questionnaire and it was voluntary for the respondents, for the age criterion was not further considered statistically). The ASTA questionnaire did not contain any further identification information about the respondents. 


\section{Statistical Analysis of Quantitative Data}

After the completed questionnaires were collected, they were visually inspected and the incompletely filled ones were sorted out. Subsequently, the data was entered into a pre-prepared matrix in the SASD (Statistical Analysis of Social Data) program. In accordance with the methodological recommendation, analyses based on the 1st and 2nd sorting stage were performed to evaluate the results of the research. The following variables were evaluated in the first sorting:

1) burden scale (ASTA symptom burden scale) - overall score

2) quality of life related to health (ASTA quality of life related to health) - overall score

3) quality of life related to health (ASTA quality of life related to health) - physical dimension

4) quality of life related to health (ASTA quality of life related to health) - mental dimension.

Calculations of absolute and relative frequencies were performed, including mean values (variance, mean, standard deviation).

Within the second sorting scale, the possible relationships between the selected variables were analysed. Through the Kolmogorov-Smirnov and Shapiro-Wilk tests, the normal distribution was first tested and on the basis of its results the relations between the variables were analysed by the Kruskal-Walis test at the significance level $\mathrm{P}<0.05$. To test the statistically significant relationship between ordinal characters, the Pearson's chi-squared test was used. At the same time, the symmetry of the relationship and the measure of the effect were analysed.

\section{Results}

The incidence of the heart rhythm disorder less than a week ago was reported in 30 (24\%) respondents; 25 respondents $(20 \%)$ reported a heart rhythm disorder one or more times a day. In 22 respondents $(17 \%)$ the heart rhythm disorder was permanent, $15(12 \%)$ had rhythm disorders less than a month ago, $17(13 \%)$ respondents experienced it 1 to 3 months ago, 11 (9\%) 3 to 6 months ago, 4 (3\%) 6 to 12 months ago, and $3(2 \%)$ respondents experienced it more than 12 months ago. All 127 $(100 \%)$ respondents answered this question.

The duration of the heart rhythm disorder lasted less than 1 hour in $46(36 \%) ; 33$ $(26 \%)$ respondents reported the duration of the heart rhythm disorder at the interval of 1 to 7 hours. In $19(15 \%)$ of respondents, the arrhythmia lasted from 7 to 24 hours, 8 respondents $(6 \%)$ experienced arrhythmia for 24 hours to 2 days, and in 5 $(3 \%)$ respondents the heart rhythm disorder lasted 2 to 7 days. 14 (11\%) respondents have a heart rhythm disorder lasting for over 7 days.

The most common symptom of arrhythmia was rapid heartbeat in 74 (58\%), followed by irregular heartbeat and a sense of heart failure one or more times. These two symptoms occurred identically in $48(38 \%)$ cases. More rapid heartbeat than usual was marked 41 times $(33 \%)$. The symptom of a short episode of heart rhythm 
disorder lasting less than 1 minute occurred in $13(10 \%), 5(4 \%)$ reported the sensation of regular heartbeat. 11 respondents $(9 \%)$ did not feel any of these symptoms.

Most respondents agreed with the claim that their heart rhythm disorder makes it impossible for them to perform work, study, and perform activities of their daily life (ADL) (figure 1).

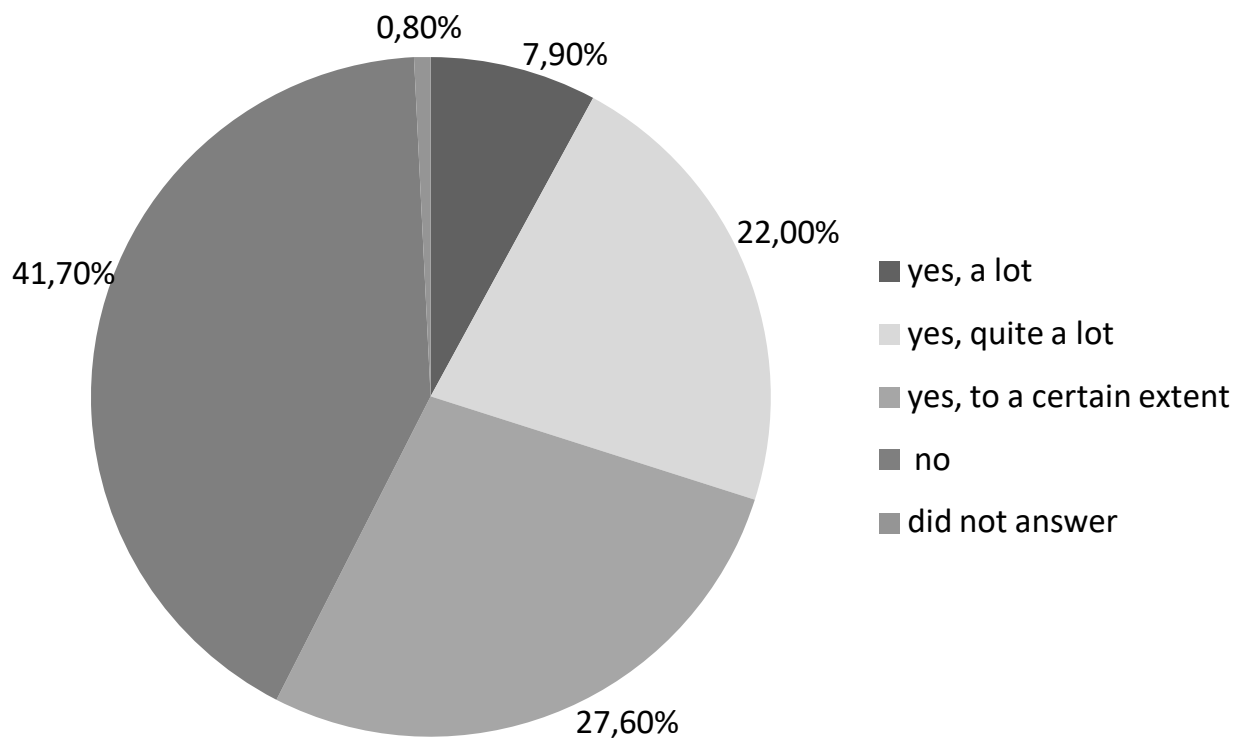

$\mathrm{n}=127$

Figure 1 Inability to perform work, study, and ADL in a arrhytmia

In the assessment of their own life situation in connection with the occurrence of their heart rhythm disorder, most respondents stated that they did not experience deterioration in their life situation (figure2). Most respondents agreed that heart rhythm disturbances prevent them from performing work tasks, studying and performing ADL (daily life activities). Yes, a lot, 10 (7.9\%) respondents chose the answer, yes, quite a lot of $28(22.0 \%)$ respondents and yes, to a certain extent 35 $(27.6 \%)$ respondents. $53(41.7 \%)$ respondents chose no. Of the $127(100 \%)$ respondents, $1(0.8 \%)$ did not respond to this question. 


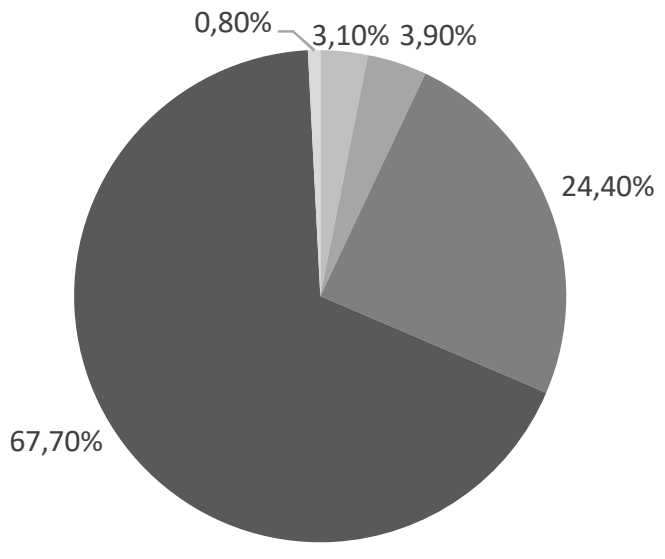

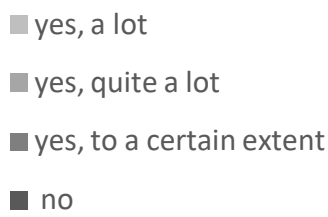

did not answer

$\mathrm{n}=127$

Figure 2 Worsening of the life situation in connection with the occurrence of a arrhytmia

The majority of respondents did not worsen the life situation due to the occurrence of heart rhythm disorder. $86(67.7 \%)$ respondents chose no. Yes, a lot, $4(3.1 \%)$ respondents chose the answer, yes, quite a lot of $5(3.9 \%)$ respondents and yes, to a certain extent $31(24.4 \%)$ respondents. Of the $127(100 \%)$ respondents, $1(0.8 \%)$ did not respond to this question.

One of the evaluated criteria was also the quality of their sleep (figure3).

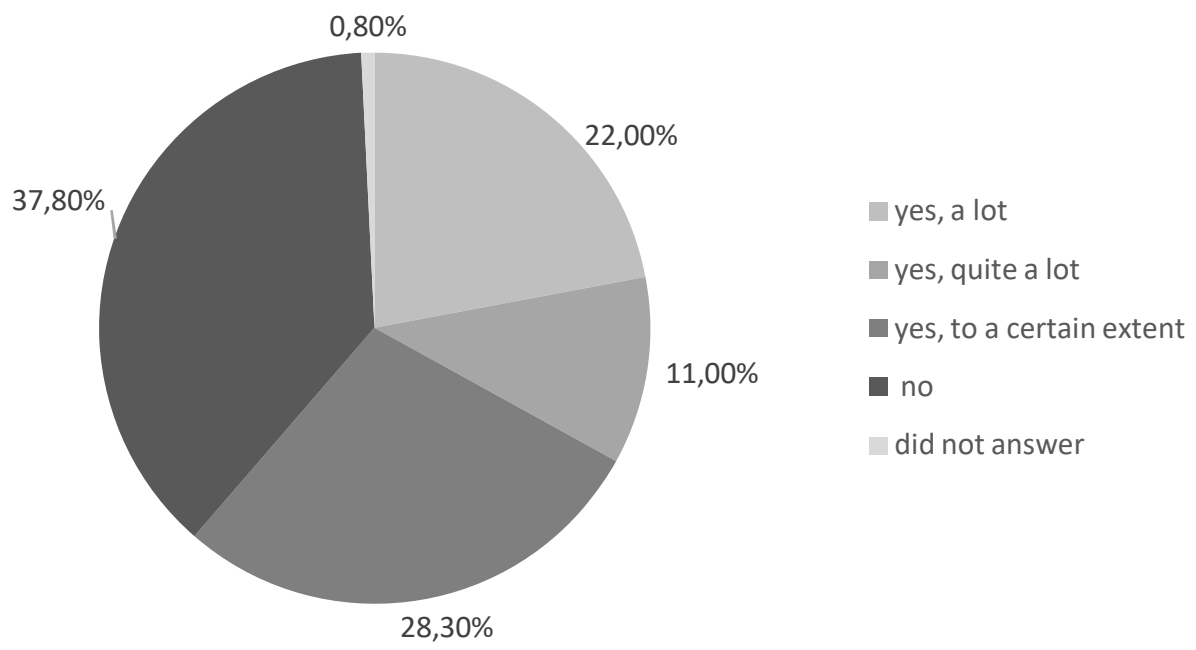

$\mathrm{n}=127$

Figure 3 Occurrence of sleep disorders 
Most respondents have sleep disorders. Yes, many, 28 (22.0\%) respondents, yes, quite a lot of $14(11.0 \%)$ respondents and yes, to some extent $36(28.3 \%)$ respondents. $48(37.8 \%)$ respondents chose no. Of the $127(100 \%)$ respondents, 1 $(0.8 \%)$ did not respond to this question.

It was further investigated whether the duration of arrhythmia had an impact on the health status and quality of life of the individual. From the point of view of the duration of arrhythmia, the group was divided into three groups according to the duration of the arrhythmia. The distribution of the respondents by category was fairly balanced (table 1,2).

\begin{tabular}{|l|r|}
\hline & frequency $(\mathrm{N}, \%)$ \\
\hline Permanent, daily & $47(37 \%)$ \\
A week or a month ago & $45(35 \%)$ \\
More than a month ago & $35(28 \%)$ \\
All & $127(100 \%)$ \\
\hline
\end{tabular}

Table 1 Duration of arrhythmia

In terms of the duration of the arrhythmia, the group was divided into 3 parts according to the categories permanent or once or several times each day, duration one week to a month and more than a month ago. The distribution of respondents by categories was relatively balanced.

\begin{tabular}{|c|c|c|c|c|}
\hline & \multicolumn{3}{|c|}{ Duration of arrhythmia } & \multirow[b]{2}{*}{$\begin{array}{l}\text { Significance } \\
\text { value* }\end{array}$} \\
\hline & $\begin{array}{l}\text { Permanent, } \\
\text { daily }\end{array}$ & $\begin{array}{l}\text { A week } \\
\text { or a } \\
\text { month } \\
\text { ago }\end{array}$ & $\begin{array}{l}\text { More } \\
\text { than a } \\
\text { month } \\
\text { ago }\end{array}$ & \\
\hline $\begin{array}{l}\text { ASTAsymp_BS ASTA } \\
\text { symptom burden scale - total } \\
\text { score }\end{array}$ & 8,21 & 7,11 & 7,21 & ,269 \\
\hline $\begin{array}{l}\text { ASTAHRQOL ASTA quality } \\
\text { of life related to health - ove- } \\
\text { rall score }\end{array}$ & 13,36 & 10,00 & 10,79 & , 186 \\
\hline $\begin{array}{l}\text { ASTAHRQOL_P ASTA } \\
\text { health-related quality of life - } \\
\text { physical dimension }\end{array}$ & 5,78 & 4,78 & 3,85 & 071 \\
\hline $\begin{array}{l}\text { ASTAHRQOL_M ASTA } \\
\text { quality of life related to } \\
\text { health - mental dimension }\end{array}$ & 7,45 & 5,22 & 6,94 & ,265 \\
\hline
\end{tabular}

* Kruskal Wallis test $\mathrm{p}<0,05$.

Table 2 Health status and quality of life 
In terms of the duration of arrhythmia, 127 respondents were divided into 3 parts according to the categories permanent or once or several times each day (47 respondents), duration one week to a month (45 respondents) and more than a month (35 respondents). The distribution of respondents by categories is relatively balanced.

To verify the hypothesis, the distribution of variables was tested. Since the variables tested were not of normal distribution, non-parametric tests were used (Kolmogorov-Smirnov, Shapiro-Wilk).

Analysis of individual categories according to the length of arrhythmia in individual ASTA dimensions was performed. Simultaneously, mean and standard deviation calculations were performed to compare individual dimensions in terms of arrhythmia duration.

The association between the duration of the arrhythmia and the overall burden symptom scale score and quality of life according to the ASTA series was tested by the Kruskal Walis test at a significance level of $p<0.05$.

Significance in each category was ASTAsymp_BS ASTA symptom burden scale (overall score) 0, 269, ASTAHRQOL ASTA health quality of life (overall score) 0 , 186, ASTAHRQOL_P ASTA health quality of life (physical dimension) 0, 071 and ASTAHRQOL_M ASTA Health-related quality of life (mental dimension) 0, 265. Despite the graphic differences in the individual variables of the ASTA series, no statistically significant differences were found. This means that the duration of arrhythmia in a given sample does not affect the general health and quality of life measured by the ASTA series.

The distribution of respondents by categories is relatively balanced. Variable distribution testing was performed. Since the variables tested were not of normal distribution, non-parametric tests were used (Kolmogorov-Smirnov, Shapiro-Wilk). Analysis of individual categories according to the length of arrhythmia in individual ASTA dimensions was performed. Simultaneously, mean and standard deviation calculations were performed to compare individual dimensions in terms of arrhythmia duration. The association between the duration of the arrhythmia and the overall burden symptom scale score and quality of life according to the ASTA series was tested by the Kruskal Walis test at a significance level of $\mathrm{p}<0.05$.

\section{Discussion}

The aim of the study was to map the quality of life of patients with heart arrhythmias. The quantitative research was focused on problems with heart rhythm disorders, following the symptoms specific to arrhythmia and the quality of life related to health in patients with heart rhythm disorders. With the help of the standardized ASTA (Arrhythmia - Specific Questionnaire in Tachycardia and Arrhythmias) questionnaire, the symptoms and changes in the quality of life, perceived by the respondents, were described. Given that the questionnaire did not contain any identification data, the respondents could complete the year of birth (the age structure of the pa- 
tients was in the range of their years of birth between 1939 - 1985); even the gender stratification of the monitored group cannot be evaluated. Because the ASTA standardized questionnaire was used in the original version and these identifiers were not added, we accepted the deficit of these possible relationships when processing statistical data.

Táborský (2015) states that arrhythmias occur either as paroxysmal, nonpermanent (ventricular tachycardia up to $30 \mathrm{~s}$ ), incessant (continuous, usually longer than 12 hours), or permanent (usually with ventricular tachycardia over $30 \mathrm{~s}$ ); similarly, $17 \%$ of respondents suffered from a permanent heart rhythm disorder, $23 \%$ reported they had arrhythmia less than a week ago, 19\% said they had a heart rhythm disorder one or more times a day. Other respondents reported that they had arrhythmias in the interval of less than one month to more than 12 months ago.

Since the first part of the ASTA questionnaire focused on finding the frequency and duration of arrhythmia, we perceived the duration factor of arrhythmia as a significant factor affecting the quality of life. In quantitative analysis, it was found that the duration of arrhythmia does not affect the quality of life of the patient with arrhythmia. The reported accompanying symptoms of heart rhythm disorder are also reported by the respondents in the questionnaire, where, for example, $58 \%$ of the respondents said the most significant manifestation of their disease is "rapid heartbeat" (palpitation). These findings were not surprising to us because even professional literature (Chrobák, 2007) lists palpitation as one of the leading symptoms of arrhythmia. Other symptoms of arrhythmias in the ASTA questionnaire were headache or dizziness, dyspnoea, weakness and faintness, fatigue, restlessness and anxiety. Also, Aliot (2014) in the AFEQT (Atrial Fibrillation Effect on Fibrillation Effect on Quality of Life) observed the symptoms that affect the quality of life of patients with atrial fibrillation and the use of measuring tools to assess the quality of life (depending on age and treatment). Also, other symptoms of arrhythmia can limit patients. Only $27 \%$ of the respondents reported that they did not experience fatigue and $28 \%$ of the patients with arrhythmias did not feel weakness or faintness. These other manifestations may limit the patient with arrhythmia in saturation of his or her own needs. During arrhythmia, patients are partially limited in their physiological needs (sleep), the need for certainty and safety may be slightly affected by temporary hospitalization or physical constraints. One of the significant physiological needs of a person is the need for sleep and rest (Tóthová et al., 2014). 61\% of the questionnaire respondents said they had problems with their sleep. Pospíchal (2018) states that in his group of patients with ischemic heart disease who underwent coronary examination, most of the patients reported the feelings of anxiety (or fear). Similarly to our research group, it was the fear of the future, the fear of incurability of the illness, the fear of the return of the disease. Another limitation in the life of a patient with arrhythmia may be the limitation of working ability. Some contexts have already been described in connection with the anxiety and inability to perform work or study duties. Chrobák et al. (2007) indicates that dyspnoea is one of the possible symptoms of arrhythmia. $43 \%$ of the respondents in the questionnaire survey stated that they did not suffer from dyspnoea when moving; 3/4 of the respondents neglected dyspnoea at rest. Pospíchal (2018) considers breathing problems as one of the significant limitations in the life of a patient with ischemic heart disease. 1/4 of the respondents 
of his research reported breathing problems or associated it with a chest pressure. Change of the patients' quality of life can also be caused by a consciousness disorder during heart rhythm disorders. Bulava (2017) states that heart arrhythmia may be one of the most common mechanisms leading to syncope. More than a quarter of the respondents in our study experienced a presyncope or syncope in connection with arrhythmia. Considering that many of these patients have long been using anticoagulant therapy for atrial fibrillation, sudden loss of consciousness and life-threatening injuries associated with subsequent bleeding may occur. The deterioration of the life situation in connection with the occurrence of a heart rhythm disorder (as one of the possibilities of life limitation) was denied by $67 \%$ of the respondents in the questionnaire survey. This proves that if the arrhythmia is not permanent, there does not have to be any significant limitations with an impact on the life situation. Another limitation in the life of a patient with arrhythmia may induce stress. Pospíchal (2018) states that in his group of patients with ischemic heart disease who underwent coronary examination, most of the patients reported the feelings of anxiety (or fear). In our research, $53 \%$ of the respondents said they did not feel the fear of dying.

At present, the concept of the quality of life is predominantly oriented to the medical plane. Doctors are interested in the quality of life of people with various illnesses or the impact of their therapy on the quality of life of the treated persons. Hnilicová (2005) states that the main focus of monitoring the quality of life in healthcare is oriented to the area of physical and psychosomatic health. Monitoring the subjectively assessed quality of life of the patient with arrhythmia allows nurses to complement the complex view of the patient and it makes it easier for nurses to plan and provide individualized nursing care.

\section{Conclusion}

The presence of heart arrhythmias significantly affects the quality of life. Heart arrhythmia restricts the patient to perform work tasks, study, and perform daily life activities. However, the sample did not show that the duration of the arrhythmia has any impact on the overall health status and quality of life measured by the ASTA series questionnaires.

\section{References}

1. ALIOT, E. G., BOTTO, L., CRIJNS, H. J., KIRCHHOF, P., 2014. Quality of life in patients with atrial fibrillation: how to assess it and how to improve it EP Europace, Volume 16, Issue 6, 1 June 2014, Pages 787-796,

2. BECH, P., 1993. Rating Scale for Psychopathology, Health Status and Quality of Life. In A Compendium on Documentation in Accordance with the DSM-III$\mathrm{R}$ and WHO Systém. Berlin: Springer.

3. BULAVA, A. 2017. Kardiologie pro nelékařské zdravotnické obory. Grada Publishing. 1. vyd. 224 s. ISBN 978-80-271-0468-0. 
4. DRAGOMIRECKÁ, E., ŠKODA, C., 1997. Kvalita života. Vymezení, definice a historický vývoj pojmu v sociální psychiatrii. Česká a slovenská psychiatrie, 93, 2, s. 102-208. ISSN 1212-0383.

5. HEŘMANOVÁ, E., 2012. Koncepty, teorie a měreni kvality života. Praha: Sociologické nakladatelství SLON. 239 s. ISBN 978-80-7419-106-0.

6. HNILICOVÁ, H., 2005. Kvalita života a její význam pro medicínu a zdravotnictví. In: Payne, J.. a kol. Kvalita života a zdraví. Praha: Triton. 629 s. ISBN 80-7254-657-0.

7. CHROBÁK et al., 2007. Propedeutika vnitřního lékařství. Praha: Grada. 243 s. ISBN 978-80-247-1309-0.

8. PAYNE, J. a kol. 2005. Kvalita života a zdraví. Praha: Triton. 629 s. ISBN 807254-657-0.

9. POSPÍCHAL, J. 2018. Porovnání kvality života a tiže onemocnění u pacienti se stabilní ischemickou chorobou srdečni podstupujíci koronarografické vyšetření. Dizertační práce. Pardubice: Univerzita Pardubice, Fakulta zdravotnických studií.

10. ROSOLOVÁ, H a kol., 2013. Preventivni kardiologie: v kostce. Praha: Axonite CZ. 248 s. ISBN 978-80-904899-5-0.

11. TÁBORSKÝ, M. a kol., 2015. Novinky v kardiologii. 1. vyd. Praha: Mladá fronta - Medical Services. 302 s. ISBN 978-80-204-3712-9.

12. TÓTHOVÁ, V. a kol., 2014. Ošetřovatelský proces a jeho realizace. Praha: Triton, 223 s. ISBN 978-80-7387-785-9.

13. USTUN, TB., COOPER, JE, DUUREN - KRISTEN S. VAN, HENDERSHOT, G., SATORIUS, M., 1994. Revision of the ICDIDH; Mental health aspect. 7th European Symposium, Viena AEP. 